"Knowledge management technology: human-computer interaction \& cultural perspective on pattern of retrieval, organization, use, and sharing of information and knowledge"

\begin{tabular}{|c|c|}
\hline AUTHORS & Tereza Raquel Merlo \\
\hline ARTICLE INFO & $\begin{array}{l}\text { Tereza Raquel Merlo (2017). Knowledge management technology: human- } \\
\text { computer interaction \& cultural perspective on pattern of retrieval, organization, } \\
\text { use, and sharing of information and knowledge. Knowledge and Performance } \\
\text { Management, 1(1), 46-54. doi:10.21511/kpm.01(1).2017.05 }\end{array}$ \\
\hline DOI & http://dx.doi.org/10.21511/kpm.01(1).2017.05 \\
\hline RELEASED ON & Wednesday, 12 July 2017 \\
\hline RECEIVED ON & Monday, 29 May 2017 \\
\hline ACCEPTED ON & Friday, 23 June 2017 \\
\hline LICENSE & $\begin{array}{l}(\mathrm{cc}) \overline{\mathrm{EY}-\mathrm{NC}} \\
\text { This work is licensed under a Creative Commons Attribution-NonCommercial } 4.0 \\
\text { International License }\end{array}$ \\
\hline JOURNAL & "Knowledge and Performance Management" \\
\hline ISSN PRINT & $2543-5507$ \\
\hline PUBLISHER & Sp. z o.o. Kozmenko Science Publishing \\
\hline FOUNDER & Sp. z o.o. Kozmenko Science Publishing \\
\hline
\end{tabular}

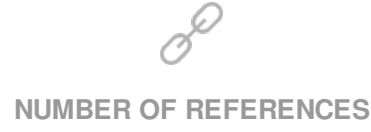

30

\section{NUMBER OF FIGURES}

1
ニニニ

NUMBER OF TABLES

0

(C) The author(s) 2023. This publication is an open access article. 


\title{
Knowledge management technology: human-computer interaction $\&$ cultural perspective on pattern of retrieval, organization, use, and sharing of information and knowledge
}

\begin{abstract}
Knowledge Management (KM) implementation is as much a challenge as it is a great opportunity for businesses worldwide in several sectors. The controversy over its worthwhile application persists among practitioners and scholars, with claims having arisen that business opportunities and performance are enhanced through KM adoption. Conversely, challenges regarding effective implementation of KM concerning individuals' behaviors, beliefs, and practices prompt significant questioning regarding its complex basis: individual-technology-process-production. The purpose of this work is to shed light on some perspectives for the effective adoption of knowledge management technology, the consolidation of a favorable and aligned organizational culture, and patterns of use and retrieval of information in organizations. This study brings into focus the concept of knowledge management and technology, and culture in the organization through a systematic literature review and based on the researcher's hypothesis and observations that successful KM implementation results from a clear understanding of its multidisciplinary, complex, and multifaceted process, which requires a methodical and strategic business practice concerning the application of technological tools, the establishment of a learning culture through shared vision of business' and individuals' needs, and consequential enhancement of processes and solutions. It concludes that investment in KM practice and the consolidation of a learning culture are correlated, reflecting a type of leadership that is favorable to the flow of information, generation, and sharing of knowledge (the intellectual capital) and optimization of decision making and business performance.
\end{abstract}

Keywords: knowledge management, KM, retrieval, use and sharing of information and knowledge, decision making, business performance.

JEL Classification: D81, D83, O34

Received on: $29^{\text {th }}$ of May, 2017.

Accepted on: $23^{\text {rd }}$ of June, 2017.

\section{Introduction}

It is unquestionable that computers have become a vital part of everyday life with a critical role in the way individuals and organizations interact. One of the most appealing aspects of the human-computer interaction $(\mathrm{HCI})$ to both practitioners and researchers is the restructure of the pattern of retrieval, organization, use, and sharing of information and knowledge. The principle of a valuable knowledge management system in the organization is to allow ways to connect the three critical elements: technology, processes, and individuals, in a manner that will promote a learning organization through the establishment of a knowledge sharing culture.

Currently, a reanalysis of the extent to which technologies have been redesigning humancomputer interactions and knowledge management

(c) Tereza Raquel Merlo, 2017.

Tereza Raquel Merlo, Ph.D. in Business and Information Technology, Adjunct Professor at the University of North Texas, 3202 Picton Court, Leander, Texas, 78641, USA.

This is an Open Access article, distributed under the terms of the Creative Commons Attribution-NonCommercial 4.0 International license, which permits re-use, distribution, and reproduction, provided the materials aren't used for commercial purposes and the original work is properly cited. is underway, and among controversies, myths, and facts, it is evident that the evolution of technology over the decades has been offering unlimited opportunities and imposing challenges to individuals and organizations worldwide.

In spite of all the advances in technological apparatuses and the simplification of information access (online), there are still many unanswered questions regarding standards for effective organizational information and knowledge management that is strongly correlated with the capability of an organization to understand and optimize its resources. The concepts and practices of a knowledge based society prompt the need for strategic production and consumption of data, information, and knowledge as a critical factor of leverage for success in an unstable and competitive global system raising questions concerning the value of learning to organizations (Rothwell, Hokne, \& King, 2011).

This relatively new process of information and knowledge management prompted by Information and Communication Technologies (ICT) advances started in the mid-1990s and has been attracting the attention of practitioners and researchers for its recognized relevance for the competitive advance of organizations in the marketplace (Lesser \& Prusak, 2004). 
The theory of Lesser and Prusak (2004) on the topic of knowledge management has contributed to a deeper understanding of how knowledge efforts are effective in improving organizational performance. It is understood as a valuable concept to be considered by organizations of all segments. The authors defend that organizations can benefit from successful management of social capital for a consolidation of a "knowledge-rich" environment that supports and reinforces the importance of effective knowledge sharing and the development of trustworthy relationships through the analysis of technology-based, information-based, and culturebased perspectives.

\section{Knowledge Management and the intellectual capital process}

Knowledge Management (KM) is an interdisciplinary field of study without a determined concept, understood as a critical part of a knowledge or economy society, progressed from a post industrial society. It suggests the systematic use of information utilizing a holistic management approach in order to create an intelligent process system in the use of resources and resolution of problems in the organization. The management of various organizational resources, including intellect and capital, is strictly related to the capability that organizations demonstrate in the management of their knowledge resources, affecting internal and external processes: employees' productivity and customer relations (Pfleging \& Minda, 2006). Firestone and McElroy (2003) defend the two processing behaviors for information and knowledge management: $\mathrm{KM}$ Production and KM Integration. According to the authors, the Knowledge Management Process (KMP): "is an ongoing, persistent, purposeful interaction among human-based agents through which the participating agents manage (handle, direct, govern, control, coordinate, plan, organize, facilitate, enable, and empower) others agents, components, and activities participating in basic knowledge processing (knowledge production and knowledge integration), with the purpose of contributing to the creation and maintenance of an organic, unified whole system, producing, maintaining, enhancing, acquiring, and transmitting the enterprise's knowledge base" (p. 71)

Knowledge Management contemplates abstract and tangible elements and all the complexity of human behavior and its creation. It involves the strategic management of intellectual capital and knowledge production. The tangible and intangible aspects of knowledge comprise the level of experience, skills, attitudes, beliefs, perspectives and values resulting from the documented and undocumented use of data and information in organizations, and shaping the intellectual capital asset (Tsoukas, 2005).

Intellectual capital, or social capital, as it is defined by many authors in the KM literature, is an essential part of knowledge management. It defines organizational identity and culture, influencing the style of thinking and use of analysis and decisionmaking in organizations. It is defined by a group of people and the way they share and create meaning over time. It is not a business strategy or marketing plan, but a practical application in business. As an intangible factor, it can be transformed into tangible goods in a knowledge-based economy. According to Geisler and Wickramasinghe (2009) intellectual capital: "is usually classified as human capital, structural capital, and relational capital. Human capital includes the knowledge, qualifications, collective capacities, skills, experiences, creativity, innovation, capability, motivation, and professional training of the employees in the organization. Structural capital includes organizational processes and procedures, hardware, software, databases, organizational structure, trademarks, patents, and intellectual property rights. Relational capital includes the value of the company's relationship with clients, suppliers, investors, and distribution channels" (p. 221).

Strategy concerns environment and organization and is considered important for its effect on the overall welfare of the organization and for providing tools to the organization to deal with changes. The challenge in the process of knowledge conversion becomes the measurement of knowledge (intellectual capital) for obtaining realistic indicators of productivity. As defended by Hlupic (2003), knowledge management is difficult to quantify in part for its unknown proportion, which remains uncodified and stored only in the minds of individuals.

Knowledge Management exists as the result of a complex mix of three elements: people, technologies, and processes, and the amalgamation of those elements in a way that information, technology, and culture are transformed and efficiently utilized. The critical factor for the competitive advantage of organizations nowadays resides in the organizational ability to recognize the complexity of the external environment and make an effective use of intellectual capital, resulting from capable people successfully utilizing technological apparatuses and willing to participate in a culture of producing and sharing knowledge (Dalkir \& Liebowitz, 2011). 
The consolidation of an organizational environment that will enable information and knowledge sharing and the intellectual capital is strongly related to the leaders' ability to support and articulate practices influencing knowledge related behaviors through providing technological (software, hardware, databases, groupware, etc.) and motivational tools (reward, continuous feedback, transparent communication, and so on) valuing individuals' ability to collectively create solutions-business intelligence. The key element for knowledge sharing effectiveness has its foundation in a set of beliefs and behaviors that will facilitate the understanding of KM tools and its applicability for performance enhancement and an individual's approach to knowledge.

\section{Technology, information and culture-based contrasts: the human-computer interaction $(\mathrm{HCl})$ interface}

KM does not have a technology-based concept, it utilizes technology tools to support and establish $\mathrm{KM}$ initiatives as part of the process. It is not the framework of KM as many would assume, defend, or imagine, but one of the elements of the process. Effective decisions on $\mathrm{KM}$ are based on people and their knowledge of process and products utilizing technology as a business strategy (Geisler \& Wickramasinghe, 2009).

Alavi and Leidner (2001) advocate that technology plays a critical role in KM process, but it represents one perspective on the broader view and understanding of $\mathrm{KM}$ in organizations, as part of the three perspectives: information-based, technologybased, and culture-based. The authors emphasize the Leavitts' model of KM culture, stressing the importance of the alignment of tasks, structure, people, and technology in organizations.

There are several theories among practitioners and researchers elaborating on the foundation of $\mathrm{KM}$ with a consensus surrounding the basic structure resulting from the effective use of information and use of technology aiming to create an organizational culture based on knowledge sharing that makes up the framework of a learning organization. Access to information and the proper strategy of how to find it constitute the information-based perspective, which contrasts with a technology-based perspective that focuses on technology, applications, and database systems, and the culture-based perspective, pertaining to how knowledge is shared among individuals in the organization. The consolidation of a culture-based perspective in this context corresponds to the organizational ability to create an environment that will be favorable to continuous learning enabling superior human performance.

Human Computer Interaction (HCI) significantly contributes to the designing of communication and information systems. It focuses on effective information exchange and social collaboration as core principle for knowledge sharing pattern. It is defined as interdisciplinary area of knowledge, studied by practitioners from disciplines such as computer science, psychology, management of information and communication systems, information science, human factors engineering, and information architecture design.

The relevance of $\mathrm{HCI}$ for KM is concerned with the ways humans interact with information and technology in a business cultural context. Zhang and Ling (2004) designed the Broad Overview of HCI, stressing that technology, human, and context aspects must support tasks. The authors examine some issues and concerns related to human and technology interaction when system is centered in design usability and use evaluation impact solely.

In the Broad Overview of HCI, the authors explain the correlation between technology, context, human, and task/job impacting design usability and use evaluation impact. In terms of technology, two types are described: basic tech and advanced tech. The first one, referring to the input, output, end user computing, organizational computing, while the second type includes information visualization, perceptual interface, embodied interface, speech technology, personalization interface, and affective computing. In terms of context, the authors describe the three aspects: global context, referring to national culture norm and universal accessibility; social context, privacy, trust, and ethics; and organizational context, organizational goals, culture, norms, policy, and management support. The human aspect of the analysis describes demographic, physical/motor, cognition level, and emotion level, while task/job comprehend the task goals and characteristic. In the center of the process Zhang and Ling (2004) stress the correlation with design usability and use evaluation impact.

In regard to information-based perspective it is strictly related to the knowledge of where the information is available for retrieval for addressing a specific issue; while the technology-based perspective focuses on the use of information systems applications to retrieve, store, and disseminate information.

The most common demonstration of the information-based perspective in organizations is 
most likely to be found in existing or emergent documents made manageable using technology systems or taxonomies. In that sense informationbased knowledge is understood as codified knowledge and is regarded as accumulated data and information (Kalling \& Styhre, 2003). Knowledge is the result of individual action and thinking. The individual is the most efficient unit of analysis for working with knowledge, and knowledge management projects strongly utilize technological components.

Information-based organizations make a strategic and proactive use of knowledge management as a competitive resource, encouraging a leadership approach that focuses on creating a trusting environment that will be conducive to knowledge sharing in a way that is aligned with the organization's purpose and strategy. The information-based perspective is based on the principle of a successful and systematic utilization of tangible resources, and is a function of the firm's know-how (Gottschalk, 2005).

Geisler and Wickramasinghe (2009) stress that due to irrelevant information available in organizations; it is the individuals' responsibility to make the determination on the validity and reliability of information and knowledge-based assets. The central idea is to manage the workforce's knowledge in a way that Nonaka and Takeuchi (1995) define as dimensions of conversion of tacit to explicit knowledge from tacit to tacit, explicit to explicit, tacit to explicit, and explicit to tacit tacit in what they defined as the "Knowledge Spiral". The Knowledge Spiral illustrates the link between tacit knowledge to explicit knowledge and tacit as a circular, continuo process, having the dialogue and "learning by doing" in the center of socialization > externalization > combination > internalization processes.

Ellis (2005) proclaims that: "Tacit or hidden/personal knowledge and explicit or coded and freely available knowledge can be held at either a personal or organizational level" (p. 38). The objective of knowledge management is to increase organizational performance (culture-based) toward supporting the development and adoption of processes and structures for the creation and sharing of knowledge among individuals in all levels of the organization.

The knowledge management dimensions stressed by Beckman (as cited in Liebowitz, 1999) involve tacit and explicit concepts, defined and categorized in terms of knowledge type-conversion, structural features, purpose, and use, as defended by Nonaka and Takeuchi (1995) on knowledge conversion based on accessibility which categorizes knowledge as tacit (socialization and internalization) and explicit (conceptual and combination). According to the theories presented by the authors, it is evident that an information-based perspective is related to the tacit and explicit concept, with the aim of ultimately generating knowledge and reflecting in the way technology is used and culture is consolidated.

The consolidation of a culture-based KM perspective enables initiatives where: "the learning organization moves on from training individuals for new skills - it is an environment that maximizes collective experience and learning, where collaborative learning benefits individuals, group and organization" (Abell \& Oxbrow, 2001, p. 33). The authors continue by arguing that the focus of the learning organization: "is not only on people and their development, but also on culture and processes, and on communities and networks" (Abell \& Oxbrow, 2001, p. 33).

According to Garvin (as cited in Harvard..., 1998, p. 51), "A learning organization is an organization skilled at creating, acquiring, and transferring knowledge, and at modifying its behavior to reflect new knowledge and insights". The author defends that a learning organization is capable of systematic problem-solving, experimentation (use of scientific methods approaching problems), learning from past experience, and striving to create a culture of transferring knowledge.

Beckman (1999) and Nonaka and Takeuchi (1995) advocate a perspective on knowledge management that follows the organizational learning cycle of acquisition, use, and dissemination of information and knowledge. The theory defended by the authors emphasizes that even in an industry and segment where KM is still perceived as a technical, softwareoriented area, the consensus around its impact on all levels of the organization is unquestionable. A broader understanding of the KM process is based on a culture that encourages information sharing, increases the capability of technology usage, and incentivizes organizational practices that will value and strategically use knowledge production and sharing.

The knowledge management pattern of retrieval, organization, and use of information in organizations encompasses four basic stages:

- Knowledge Acquisition (defining rules and ontology gathering information: Artificial Intelligence, Information Architecture, etc.). 
- Knowledge Organization (Data Mining, Data Warehouse, Databases, Workflows, etc.).

- Knowledge Sharing (exchange of information/knowledge between and among individuals).

- Knowledge Use (transformation from tacit to explicit and the application of knowledge acquired).

These stages are implemented throughout the process of information flow in all levels of the organization, as exemplified in Figure 1 below:

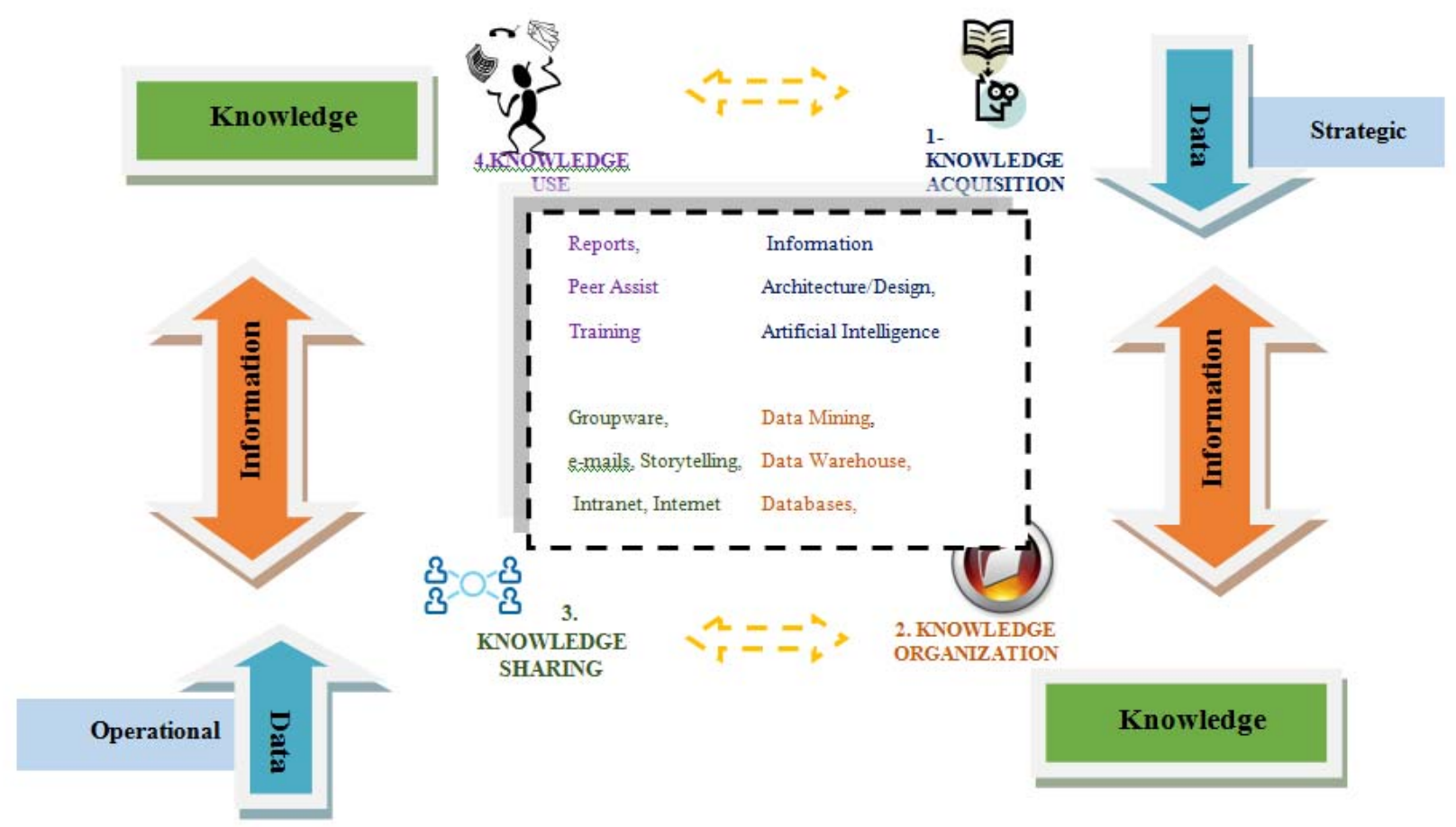

Fig. 1. Cultural perspective on pattern of retrieval, organization, use, and sharing of information and knowledge

Classic theorist in the field on Knowledge Management, Davenport and Prusak stress the critical role of human attitudes and interpersonal behaviors for effectiveness of knowledge organizations in the "knowledge Markets". The authors point out how software is unlikely to solve any knowledge problem and how informal conversations among employees in fact constitute a marketplace in which buyers and sellers trade insight, advice, experience, and lessons for range of desirables such as trust, reputation, and status (as cited in Stricker, 2014, p. 35).

3. The role of computer technology in capturing, analyzing, using, and evaluating organizational knowledge: some considerations

Intense use of Information Technologies (IT) in organizations has facilitated the process of knowledge conversion to explicit through the rationalization of information, capable storage and transmission of information, and the capability to represent information in the form of documents, including a digital format transmissible in multiple formats through worldwide applications. The conversion between information and knowledge is efficiently accomplished though people and the organization must create a culture to expand and develop knowledge across an organization that can facilitate collation and dissemination of data and information, and as a result, consolidate the knowledge resource.

Knowledge Management enables the development of mechanisms to transform and convert tacit and explicit knowledge that surrounds intellectual capital, leveraging individuals' understanding and organizational capabilities to attain the enterprise's ultimate goals and intellectual capital (Despress \& Chauvel, 2000). It also enables the culture-based perspective that focuses on knowledge sharing and the clear understanding that individuals' expertise and sets of skills are decisive for organizational efficiency. 
In a knowledge economy when the management of intellectual capital is a critical factor in organizational survival, the emphasis is on the capability of organizations to incorporate innovative solutions to entrench their position in the market. The key becomes to effectively manage human, technological, and other resources and leaders are left with the challenge of optimizing the utilization of organizational resources contemplating the business core.

The role of Information Technologies in KM processes is to enable initiatives and play a critical role in the integration of the concept of knowledge representation and transformation. IT facilitates the sharing of knowledge and expertise through global network computers and groupware and uses the processing of knowledge as a tool to support social activity in cultural-based knowledge management and solutions (Wang et al., 2001). It enables the utilization of an information infrastructure and repository which facilitates the information retrieval process and builds a more effective generation of knowledge process.

The way individuals make sense of their organizational context, build knowledge, utilize information, and form understanding is affected by their identity and affects the work environment, forming the culture of the organization. This constitutes the knowledge-based organization and defines the information processing structure, from perceiving and selecting information to its use and communication. According to Rothwell et al. (2011), the Human Performance Improvement (HPI) approach focuses on results, outcomes and accomplishments with emphasis on behaviors concurrently allowing the analysis of performance gaps, strategic planning for superior human performance improvement, and the development of cost-effective interventions.

Knowledge Management is driven by external and internal factors, most critically by competition, marketplace demands, the adoption of new processes and management styles, and information systems available, along with the globalization of business, customers, and suppliers, collaborate for the enterprise's effectiveness, technological capabilities, and human cognitive functions (Despress \& Chauvel, 2000).

Information and knowledge management are critically affected by advances in computing and multiple tools of communications technology, prompting organizational changes in management structure and the workplace dynamic as a whole. Castells (2010) defines the competitive market as the result of the intense use of information and communication technologies consolidating the knowledge of economy.

Davenport (2005) defines knowledge workers as individuals with a superior level of expertise, education, and experience, assuming positions where the use and creation of knowledge is high. According to the author, there are a series of traits and techniques applied to identify and address knowledge workers, and the use of technology solutions is relevant for knowledge workers. The author notes difficulties in managing knowledge workers and implementing changes.

The key, according to Davenport, is to incorporate tools that will improve processes and productivity of knowledge workers through the adoption of welldesigned information systems and solid social networks. Davenport (2005) notes that knowledge workers are susceptible to practices in management style to feel encouraged and empowered to participate in the KM process: consuming, producing, and sharing information and knowledge.

Some of the challenges in KM implementation and knowledge workers' management reside in human factors and the resistance individuals demonstrate whenever facing situations of changes, whether it is management change or simply process changes due to the implementation of new information systems. An organization that promotes and supports learning will allow individuals to express themselves through experimentation and open dialogue.

McElroy (2003) theorizes on a "second generation knowledge management (KM)" or "supply-side KM", delimitating a foundation for achieving sustainable innovation by focusing on the production and processes involved in KM. The author presents "The Knowledge Life Cycle (KLC)" diagram indicating the correlation between production, integration, and feedback in the knowledge process. McElroy provides a foundation to be explored and applied by managers as a method of improving the process of knowledge in organizations, as well as optimizing the understanding of how investments in KM affect individuals and business performance. According to the author, proper investments in KM contribute to advances in the way knowledge is processed and generated in the organization, resulting in effective strategic decisions, competitive advantage, and superior business performance.

Nissen (2006) highlights the relevance of knowledge initiatives for the competitive advantage of organizations and their ability to find solutions at 
a fast pace. Furthermore, the identification of intellectual capital and knowledge assets available in the organization must be strategically utilized by managers. The systematic approach to KM sees people, processes, and technology as a unified system and social software is to be used in an articulated manner, so that collaboration is encouraged and supported, and knowledge is captured and consistently shared.

Jarvenpaa and Staples (2001) elaborated on organizational ownership of knowledge, pointing out that collaborative initiatives bring internal (intraorganizational) and external (interorganizational) benefits to an organization. The success of KM initiatives relies on the organization's ability to concentrate more on people and less on technology, especially considering that individuals are more likely to express themselves and share experiences and information in an informal manner (Ward \& Peppard, 2002).

The emphasis within this context is that behavior modification in organizations is traditionally classified as: positive reinforcement, avoidance learning, extinction, and punishment, with positive reinforcement as the most used in knowledge management environments. According to Amar (2002): “As shift takes place toward knowledge organizations (intellectual organizations), understanding work becomes very complex, and work behavior becomes hard to comprehend, to model, and to modify" (p. 51).

The work environment manifests the organization's culture, and the level of knowledge is used by the organization to encourage a culture of trust, freedom, and control. The knowledge flow management in organizations is embedded in the organization's overall strategy, considering the combination of human, technological and informational resources as critical factors of success.

Organizations in a knowledge society are expected to optimize human and technological resources toward building constant learning processes. Gottschalk (2005) defends that technological advances optimize the dissemination of information, creating a culture that goes beyond an informationbased or technology-based perspective. It imposes the urgency of an organizational culture that will connect all aspects of the organization and enable knowledge sharing.

The definition of knowledge society presented by Hislop (2013) stresses the increased use of information, knowledge, and technology in many industries and organizational segments as the result of a post-industrial process where: "the service sector is dominant and knowledge based goods/services have replaced industrial, manufactured goods as the main wealth generators" (p. 5). This process presents opportunities and challenges to organizations in the sense that significant changes in services and products alter the nature of the work itself, substantially increasing the examination of how successful the elements of change (technology and information design) are at leveraging tacit knowledge of employees and improving organizational performance.

The more processes become computerized the more organizations perceive the need to focus on management functions and responsibilities and on the strategic function of the organization. The paradigm shift imposes an increased need for reevaluation of the traditional data-knowledge model and organizational environment (information processing, knowledge resources, and technological apparatuses) toward building a dynamic information infrastructure.

In a knowledge-based economy there is a pressing need for knowledge workers as a key strategy to generate economic growth and tangible assets, measured as capital investment (Hlupic, 2003), which combined with information technology and network infrastructure create value for an organization and ensure competitive advantage.

\section{Conclusion}

The production and use of knowledge in organizations has increasingly become the topic of attention and discussion among practitioners and researchers for its value in the development of effective organizational strategies and competitive advantage. With knowledge becoming the key asset in the defined knowledge economy, organizations must reinvent themselves in order to encourage and promote the creation and use of knowledge by the workforce, creating a work environment that is flexible, creative, and positive to knowledge workers.

The purpose of knowledge management is to contribute to the consolidation of an organizational culture that will enable individuals to effectively create and share knowledge, potentially reflecting in a reduction of errors, optimization of time, and increase in efficiency in decision making. The adoption of $\mathrm{KM}$ is proven to increase profitability and innovation through creativity, collaboration, and responsiveness (Gottschalk, 2005). 
The emphasis on the three critical aspects of KM (people, technology, and process-culture) is attributed to investments in individuals (motivation, recognition, reward, and self-realization), the ability to adopt, implement, and use technological solutions (cost versus benefits), culture, and the creation of a learning environment that is favorable to knowledge production and a competitive advantage. These dimensions utilized to approach $\mathrm{KM}$ in an organization are applied according to management style in different perspectives of information-based, technology-based, and culture-based principles, providing a new dimension to the human-computer interaction process.

Those three perspectives are associated with the level of effectiveness managers express when encouraging and creating a KM culture-based environment. Organizations and leaders nowadays are expected to enable the use of information technologies by supporting, encouraging, and creating a work environment that will be favorable to knowledge production and sharing, foster cooperation, and implement performance-evaluation processes that will reward the sharing of knowledge and increase individuals' ability to retrieve and use relevant information at a fast pace. The use of knowledge management techniques must ensure the appropriate management of sophisticated intangible and tangible assets (information, technology, and culture) in the organization in order to ensure a competitive advantage.
The evolving practice of knowledge management introduces to organizations a dimension of challenges and opportunities that suggests the emergence of a style of leadership that will be more collaborative than controlling, willing to reunite efforts toward building a culture of constant learning, fostering creativity, participation, and innovation. The Human Performance Improvement (HPI) approach defended by Rothwell et al. (2011) is an example of an influential tool that can be used to help build intellectual capital, establish and maintain a highperformance workplace, enhance profitability, and encourage productivity.

The organizational learning process is still in consolidation and values intellectual capital investments as much as technological assets, recognizing that effective organization and management of data, information, and knowledge are crucial to transform business decisions and produce creative solutions to organizational challenges in the midst of a revolving economy and competitive market. A pattern of retrieval, organization, storage, and sharing of information and knowledge enable a decentralized and faster flow of information, fostering an environment that attracts knowledgeable specialists, cutting edge computer technologies, and a culture of sharing and learning that encourages problem solving and productivity.

\section{References}

1. Abell, A., \& Oxbrow, N. (2001). Competing with Knowledge: The information professional in the knowledge management age. London: tfpl Library Association Publishing.

2. Alavi, M., \& Leidner, D. E. (2001). Review: Knowledge Management and Knowledge Management Systems: Conceptual Foundations and Research Issues. MIS Quarterly, 25(1), 107-136. https://dx.doi.org/10.2307/3250961

3. Amar, A. D. (2002). Managing knowledge workers: unleashing innovation and productivity. Westport: Quorum Books.

4. Beckman, T. J. (1999). The current state of knowledge management. In Liebowitz, J (Ed.), Knowledge management handbook (pp. 1-1-1-22). Washington: CRC Press.

5. Castells, M. (2010). The rise of the network society. Cambridge: Blackwell Publishers.

6. Cooper, D. R., \& Schindler, P. S. (2011). Business research methods (11th ed.). New York, NY: McGrawHill/Irwin.

7. Dalkir, K., \& Liebowitz, J. (2011). Knowledge management in theory and practice. Massachusetts: Massachusetts Institute of Technology.

8. Davenport, T. H. (2005). Thinking for a Living. Boston, MA: Harvard Business School Publishing.

9. Despres, C., \& Chauvel, D. (Eds.). (2000). Knowledge horizons: the present and the promise of knowledge management. Boston: Butterworth Heinemnn.

10. Earl, M. J. (2001). Knowledge management strategies: Toward a taxonomy. Journal of Management Information Systems, 18(1), 215-233. https://dx.doi.org/10.1080/07421222.2001.11045670

11. Ellis, S. (2005). Knowledge-Based Working: Intelligent operating for the knowledge age. England: Chandos Publishing.

12. Firestone, J. M., \& McElroy, M. W. (2003). Key issues in the new knowledge management. New York: Butterwoth Heinemann.

13. Geisler, E., \& Wickramasinghe, N. (2009). Principles of Knowledge Management: theory, practice, and cases. England: M. E. Sharpe.

14. Gottschalk, P. (2005). Strategic Management Technology. London: Idea Group Publishing. 
15. Harvard Business Review on Knowledge Management (2000). Boston: A Harvard Business Review Paperback.

16. Hislop, D. (2013). Knowledge Management in organizations: a critical introduction. New York: Oxford University Press.

17. Hlupic, V. (2003). Knowledge and business process management. United Kigdom: IDEA Group Publishing.

18. Jarvenpaa, S. L., \& Staples, S. (2001). Exploring perceptions of organizational ownership of information and expertise. Journal of Management Information Systems, 18(1), 151-183. Retrieved from http://www.jstor.org/stable/40398520

19. Kalling, T., \& Styhre, A. (2003). Knowledge sharing in organizations. Liber: Copenhagen Business School Press.

20. Lesser, E., \& Prusak, L. (2004). Creating value with Knowledge: insights from the IBM Institute for Business Value. New York: Oxford University Press.

21. McElroy, M. W. (2003). The New Knowledge Management: Complexity, Learning, and Sustainable Innovation. Burlington, MA: Butterworth-Heinemann.

22. Nissen, M. E. (2006). Harnessing Knowledge Dynamics: Principled Organizational Knowing \& Learning. Hershey, PA: IRM Press.

23. Nonaka, I., \& Takeuchi, H. (1995). The knowledge creating company: how Japanese companies create the dynamics of innovation. London: Oxford University Press.

24. Nonaka, I., Toyama, R., \& Konno, N. (2000). SECI, Ba and leadership: A unified model of dynamic knowledge creation. Long Range Planning, 33(1), 5-33. https://doi.org/10.1016/S0024-6301(99)00115-6

25. Pfleging, B., \& Zetlin, M. (2006). The geek gap: why business and technology professionals don't understand each other and why they need each other to survive. New York: Prometheus Books.

26. Rothwell, W. J., Hokne, C. K., \& King, S. B. (2011). Human Performance Improvement: building practitioner performance. New York: Routledge.

27. Tsoukas, H. (2005). Complex Knowledge: Studies in Organizational Epistemology. Oxford, England: Oxford University Press.

28. Wang, K., Hjelmervik, O. R., \& Bremdal, B. (2001). Introduction to knowledge management. Norway: Tapir Academic Press.

29. Ward, J., \& Peppard, J. (2002). Strategic planning for information systems. UK: Wiley.

30. Zhang, P., \& Li, N. (2004). An assessment of human-computer interaction research in management information systems: Topics and method. Computers in Human Behavior, (20)2, 125-147. https://doi.org/10.1016/j.chb.2003.10.011 